\title{
Hydrophilus (Dibolocelus) palpalis (Coleoptera, Hydrophilidae, Hydrophilinae): descrição dos estágios imaturos
}

\author{
Márcia M. D. de Oliveira ${ }^{1}$, Cristiano Dalla-Rosa ${ }^{1}$, Leonardo H. Matias ${ }^{1}$ \& Juan A. R. Cueto ${ }^{2}$ \\ 1. Museu de Ciências Naturais, Laboratóro de Entomologia, Universidade de Caxias do Sul, Rua Francisco Getúlio Vargas, 1130 , \\ 95070-560 Caxias do Sul, RS, Brasil. \\ 2. Departamento de Biologia Animal, Universidade de Leon, Luis de Sosa, 24071, Leon, Espanha.
}

\begin{abstract}
Hydrophilus (Dibolocelus) palpalis (Coleoptera, Hydrophilidae, Hydrophilinae): description of the immature stages. Egg case, larvae and pupa of Hydrophilus (Dibolocelus) palpalis are described and illustrated. The aquaria-terraria method was used to rear immature instars in the laboratory.
\end{abstract}

KEYWORDS. Hydrophilus (Dibolocelus), Hydrophilidae, immature stages.

\section{INTRODUÇÃO}

Os estágios imaturos da maioria dos gêneros de Hydrophilidae já foram descritos, porém, em alguns grupos, a ausência de publicações tem dificultado o trabalho dos poucos taxonomistas que atuam nesta área.

Das onze espécies do subgênero Dibolocelus, apenas Hydrophilus (Dibolocelus) ovatus Gemminger \& Harold, 1868, teve suas formas imaturas descritas.

A importância dos estágios larvais dos hidrofilídeos é reconhecida em muitos aspectos: são excelentes fontes alimentares de peixes; agem como predadores de larvas de outros insetos aquáticos que possuem importância econômica ou médica, como os quironomídeos e culicídeos; auxiliam no controle de outros invertebrados e ainda a maioria das espécies pode predar populações de peixes e girinos (WILSON, 1923a, b). Em estudos ambientais podem ser extremamente úteis como indicadores de qualidade da água.

Objetivou-se descrever os estágios imaturos de Hydrophilus (Dibolocelus) palpalis Brullé, 1837, elucidando alguns aspectos da biologia e de seu comportamento.

\section{MATERIAL E MÉTODOS}

O material utilizado no desenvolvimento do ciclo biológico de $H$.(D.) palpalis em laboratório foi coletado em janeiro de 2001, em Cachoeirinha, RS.

Para a descrição dos estágios imaturos foram utilizados 20 adultos de $H$.(D.) palpalis, que geraram 3 posturas, 38 larvas ( 9 do terceiro instar, 12 do segundo instar e 17 do primeiro instar) e uma pupa, fixada em água quente e conservada em álcool $70 \%$. Todo o material estudado está depositado na coleção entomológica do Museu de Ciências Naturais da Universidade de Caxias do Sul (exemplares adultos $n^{\text {os }} 792,803,804,806,807,808$, $818,820,821,834,933,973,975,976,977,987,988,989,990$ e 1189).

Seguindo Archangelsky \& Durand (1992), para a alimentação das larvas foram oferecidos moluscos encontrados no mesmo ambiente em que foram coletados os adultos.

\section{RESULTADOS E DISCUSSÃO}

Postura $(n=3)$. Para a construção da bolsa de ovos, a fêmea utiliza alguma folha que esteja flutuando na superfície do aquário. Primeiramente tece a parte superior da bolsa sob a folha, após a inferior e em seguida, a posterior, deixando uma abertura na região anterior onde são depositados os ovos, para então ser fechada definitivamente. Na base posterior da bolsa está o mastro, de aspecto tubular, voltado para cima (fig. 1). A bolsa de ovos, constituída de seda branca, mede em média $17,5 \mathrm{~mm}$ de largura, $14,5 \mathrm{~mm}$ de profundidade e cerca de $24 \mathrm{~mm}$ de altura, incluindo o mastro, de cor marrom-acinzentada. $\mathrm{O}$ mastro promove a estabilidade e previne a rotação da bolsa de ovos. A bolsa flutua na superfície da água até os ovos eclodirem, o que ocorre cerca de uma semana após a postura.

As posturas tiveram em média 35 a 45 ovos amareloclaros, cada um em forma semelhante a bastonete (figs. 13) e medindo cerca de 3,7 a 3,9 mm de comprimento e $1 \mathrm{~mm}$ de largura.

Larvas de $1^{\circ}$ instar $(n=17)$. As larvas saem por uma cavidade na base do mastro; medem cerca de $12 \mathrm{~mm}$ e atingem $23 \mathrm{~mm}$ no final do instar, que dura de 8 a 10 dias. Apresentam-se muito ativas, sempre na procura por alimento. Neste período são marrom-claras, com o abdômen recoberto de cerdas.

Larvas de $2^{\circ}$ instar $(n=12)$. Coloração mais escura que no instar anterior, tanto na cabeça quanto no abdômen. Dimensões: aproximadamente $24 \mathrm{~mm}$, atingindo $38 \mathrm{~mm}$ após 15 a 20 dias.

Larvas de $3^{\circ}$ instar $(n=9)$. Inicialmente, a cabeça é esbranquiçada, tornando-se preta no decorrer do tempo. O corpo permanece marrom-escuro (fig. 10). Comprimento: 33 a $63 \mathrm{~mm}$; largura do abdômen: 7 a $11 \mathrm{~mm}$. Escleritos cervicais ovais, encobertos pelo pronoto, visíveis quando a cabeça está voltada para baixo. Cutícula do tórax e do abdômen coberta por dois tipos de placas: as achatadas, mais numerosas, semelhante a estrelas, e as cônicas (fig. 13). Cápsula cefálica oval, endurecida, de tonalidade escura (fig. 6); dorsalmente, duas suturas: uma na porção anterior da cabeça, disposta entre as bases laterais internas das antenas, e uma outra bem definida, estende- 

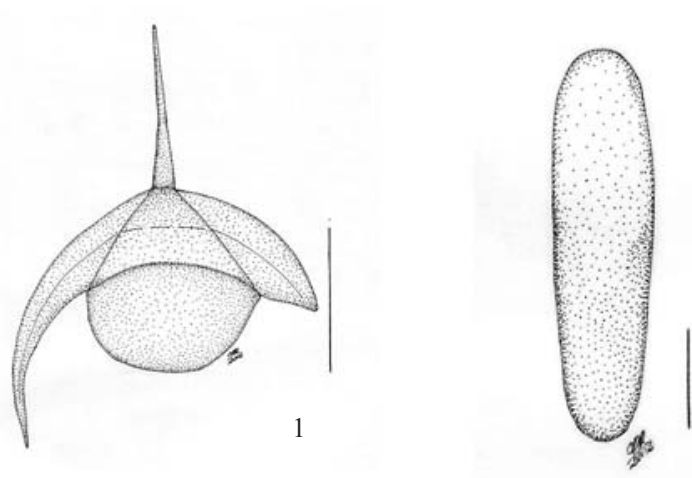

3

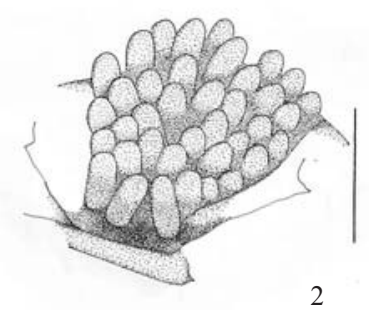

Figs. 1-3. Hydrophilus (D.) palpalis: 1, postura sob folhas; 2, disposição dos ovos na postura; 3, ovo. Barras: figs. 1, 2, 10 mm; fig. $3,1 \mathrm{~mm}$.

se da base interna da antena até a borda central do forame occipital e fusiona-se antes de atingir a margem superior. Superfície dorsal da cápsula cefálica com poucas cerdas, localizadas principalmente nas margens laterais. Nas superfícies dorsal e ventral da cápsula cefálica há uma série de pontuações. Áreas oculares, uma de cada lado da cabeça, com 6 estemas arranjados em duas colunas oblíquas (fig. 8). Antenas com 4 segmentos (fig. 5), segmento basal mais largo e longo que os outros, dotado de cerdas pequenas na parte ventral interna e várias maiores externamente; segundo segmento muito pequeno, sem cerdas; e terceiro com duas cerdas pré-apicais curtas; último segmento semelhante ao anterior, porém mais fino. Labro-clípeo simétrico, com ondulações na margem anterior (fig. 7) e uma pequena projeção anterior. Projeções ânterolaterais do epistoma menores e mais longas que o labroclípeo, cada uma com duas longas cerdas direcionadas para a frente. Labium robusto (fig. 9); penúltimo segmento menor que o apical, sem cerdas; extremidade do último segmento com várias cerdas pequenas. Lígula reduzida. Palpígero sub-retangular, em vista dorsal com várias cerdas laterais. Mentum com duas projeções laterais triangulares robustas e pequenas cerdas por toda a superfície. Mandíbulas assimétricas: a direita fina, na porção mediana interna um dente retangular robusto usado como dente molar para quebrar a concha de moluscos (fig. 12); a esquerda, pouco menor, com um dente triangular na parte mediana interna e um na direção basal interna, que serve para manter as conchas em posição para serem quebradas (fig. 11). Maxila mais longa que a antena (fig. 4); primeiro segmento mais longo que os outros quatro juntos, com vários espinhos longos projetados na porção interna e outros menores na parte dorsal e externa; espinhos da porção basal menores que os da porção interna e maiores que os da parte dorsal externa; segundo segmento sustentado por um anexo esclerotizado triangular na região basal externa, com uma cerda na margem interna da porção anterior e uma mais larga que as demais na parte apical interna; terceiro segmento com base interna esclerotizada. Protórax posteriormente mais largo que a cabeça. Pronoto formado por dois escleritos subquadrados que cobrem a maior parte da superfície dorsal, tendo uma linha sagital aparente. Mesotórax e metatórax com dois escleritos subtriangulares. Pernas com quatro segmentos (figs. 15-17): coxa longa, com fileira de pêlos na margem dorsal; trocanter curto e pubescente na porção ventral; fêmur pouco mais longo que a coxa, com fileira de pêlos nas margens ventral e dorsal; tíbia e tarso pouco menores que o fêmur, com fileira ventral de pêlos curtos e espessos; pré-tarso fino e pontiagudo.

Segmentos abdominais 1 a 8 com espiráculos dorso-laterais abertos; primeiro segmento mais curto que os sete seguintes; $2^{\circ}$ ao $6^{\circ}$ com tamanho e forma semelhantes; $7^{\circ}$ e $8^{\circ}$ mais longos e estreitos; segmentos 9 e 10 reduzidos. A segmentação abdominal é confusa devido a dobras transversais, tanto na parte dorsal quanto na ventral; assim, cada segmento pode parecer três. Lateralmente um par de lóbulos (um de
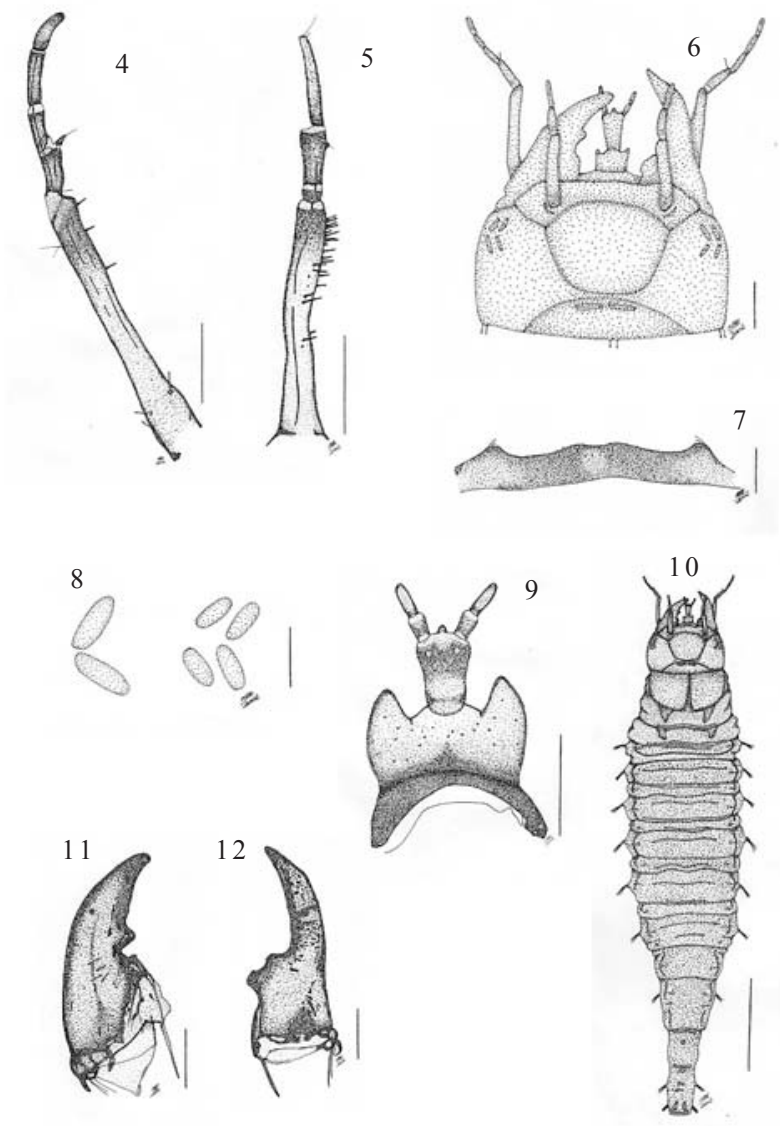

Figs. 4-12. Hydrophilus (D.) palpalis, larva de $3^{\circ}$ instar: 4, maxila esquerda, dorsal; 5 , antena, dorsal; 6 , cabeça, dorsal; 7, labro-clípeo, ventral; 8, estemas; 9, labium, ventral; 10, habitus, dorsal; 11, mandíbula esquerda, dorsal; 12, mandíbula direita, dorsal. Barras: figs. 4-9, 11, 12, $1 \mathrm{~mm}$; fig. 1), $10 \mathrm{~mm}$. 


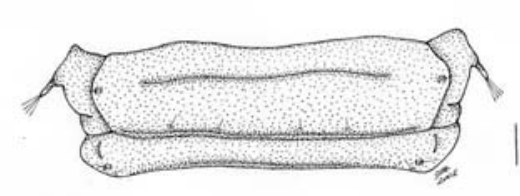

13

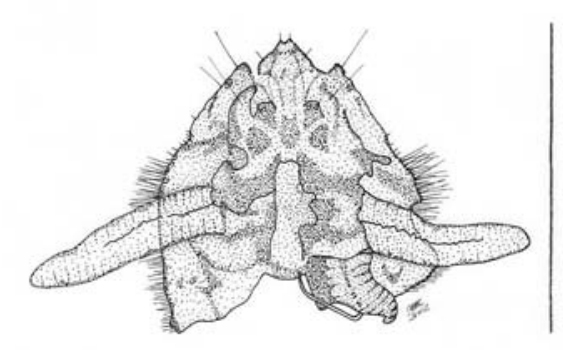

14

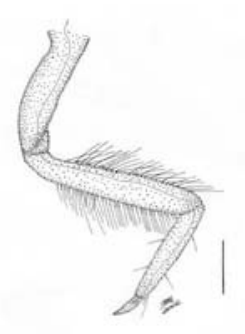

15

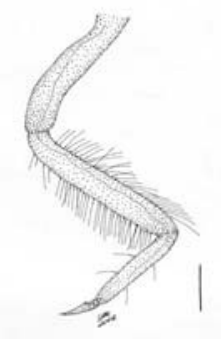

16

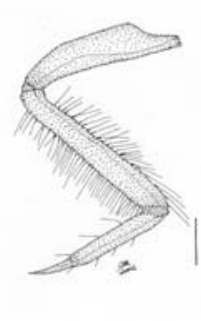

17
Figs. 13-17. Hydrophilus (D.) palpalis, larva de $3^{\circ}$ instar: 13, segmento abdominal, dorsal; 14, atrium espiracular, ventral; 15, perna I, ventral; 16, perna II, ventral; 17, perna III, ventral. Barras: $1 \mathrm{~mm}$.

cada lado), cada um com cerdas longas. Pequenos tubérculos dispostos dorso-lateralmente, com cerdas nas extremidades. Oitavo segmento forma um átrio estigmático (fig. 14) que porta o último par de espiráculos. Dois escleritos laterais subtriangulares com algumas cerdas na sua porção posterior do nono segmento. Na porção ventral do oitavo segmento, dois anexos tubulares delgados.

Este instar é o de período mais longo, durando até 40 dias.

Pupa $(n=1)$. Das larvas que procuraram terra úmida, apenas uma formou câmara pupal, onde permaneceu cerca de duas semanas até constituir a pupa, com comprimento cerca de $32 \mathrm{~mm}$ e largura aproximadamente $16 \mathrm{~mm}$ (figs. 18-19); coloração branco-amarelada; olhos amarelo-claros a marromclaros. Corpo glabro. Cabeça com sutura epicranial transversal mediana, partindo da porção posterior até o centro da cabeça e, no final desta, partem duas suturas, uma para cada lado até a base inferior dos olhos, formando um "Y" invertido; margem posterior da cabeça com duas pequenas elevações, uma a cada lado da sutura mediana; porção anterior da cabeça com duas suturas, uma transversal entre a base dos olhos, e outra longitudinal na porção mediana. Antenas inseridas na base anterior dos olhos, contornando-os e ocultando-se abaixo do pronoto. Palpo maxilar alcança a base do mesonoto. Pronoto com 3 grandes estilos a cada lado da margem anterior (fig. 20), cerca de $4 \mathrm{~mm}$ cada um; 3 estilos em cada ângulo lateral posterior e 11 pequenos estilos ao longo da margem posterior. Mesonoto com um estilo a cada lado do escutelo. Metanoto com um estilo em cada lado.

Tíbia do $1^{\circ}$ e $2^{\circ}$ pares de pernas com dobras antefemurais, sem cerdas ou pêlos; $3^{\circ}$ par de pernas coberto, em parte, pelas asas; apenas a porção posterior do fêmur, a tíbia e tarso visíveis. Pró- e mesotíbia com espinho apical visível. Metatíbia com dois espinhos apicais, o lateral menor. Espinho mesosternal longo, alcançando a margem anterior do $4^{\circ}$ segmento abdominal.

Segmentos abdominais 1 a 7 com 6 estilos cada, um par distribuído a cada lado da linha mediana, um par de longos estilos $(4 \mathrm{~mm})$ atrás dos espiráculos; $3^{\circ}$ par visível apenas em vista lateral ou ventral, nas margens laterais dos segmentos abdominais. Nono segmento com dois longos cercos no ápice $(4 \mathrm{~mm})$ e estruturas semelhantes a pernas, com 3 a 4 segmentos no macho (fig. 21).

Comparando a descrição dos imaturos de Hidrophilus (D.) ovatus Geminger \& Harold, 1868 a Hidrophilus (D.) palpalis, Brullé, 1837, constatou-se
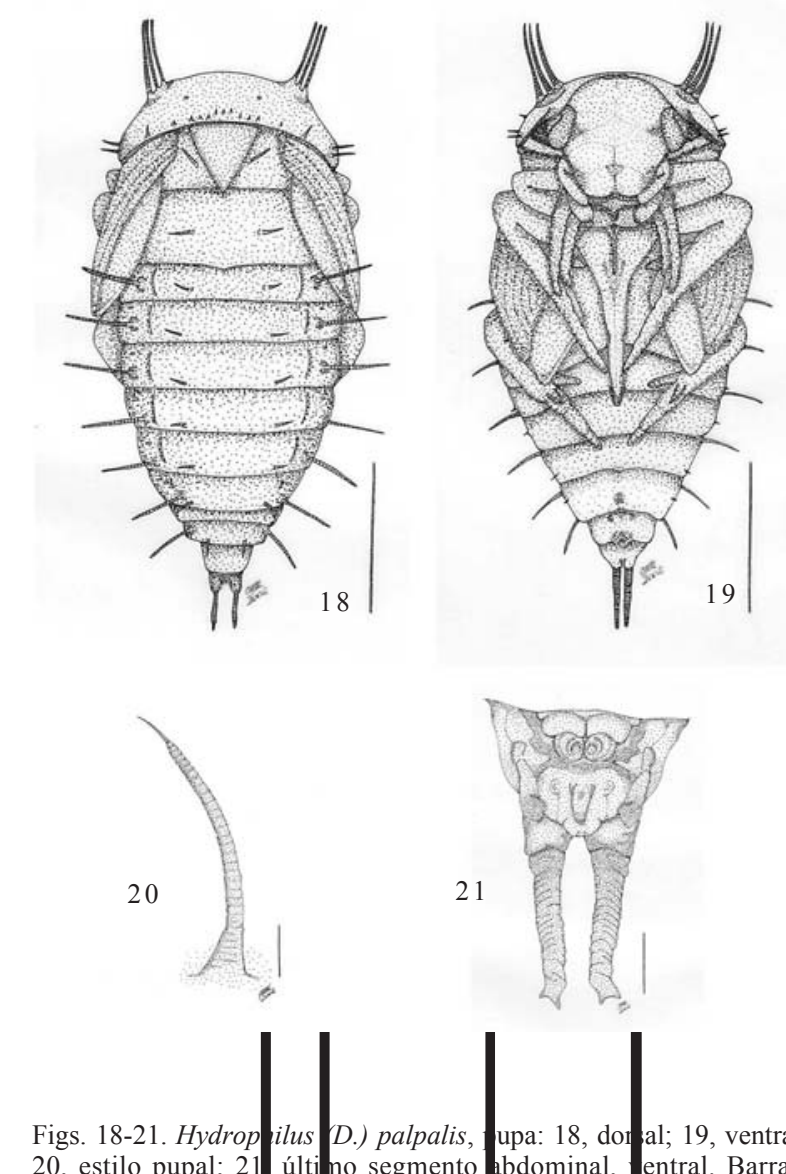

20, estilo pupal; 21 últi no segmento abdominal, figs. $18,19,10 \mathrm{mr}$; fig s. 20, 21, $11 \mathrm{~lm}$. 
que a única diferença está na pupa, onde a primeira espécie apresenta 4 pequenos estilos na parte mediana da margem anterior do pronoto.

Agradecimentos. Ao Jaime Vargas de Oliveira (Instituto Riograndense do Arroz), pela disponibilização da área para coleta. Ao Museu de Ciências Naturais, Fundação Zoobotânica do Rio Grande do Sul, pelo empréstimo de material para estudo. À Universidade de Caxias do Sul e Universidade de Léon, pelo apoio no desenvolvimento do trabalho. À bióloga Janete Maria Scopel, acadêmico Gerson Cavalli, Eliana Teresinha Verona, da Universidade de Caxias do Sul, e demais pessoas que tornaram possível a realização deste trabalho.

\section{REFERÊNCIAS BIBLIOGRÁFICAS}

Archangelsky, M. \& Durand, M. E. 1992. Description of the preimaginal stages of Dibolocelus ovatus (Gemminger \& Harold, 1868) (Coleoptera, Hydrophilidae, Hydrophilinae). Aquatic Insects, Lisse, 14(2):107-116.

WiLson, C. B. 1923a. Water beetles in relation to pondfish culture, with life histories of those found in fishponds at Fairport, Iowa. Bulletin of the United States Bureau of Fisheries, Washington, 39:231-345.

1923b. Life history of the scavenger water beetle Hydrous (Hydrophilus) triangularis, and its economic relation to fish breeding. Bulletin of the United States Bureau of Fisheries, Washington, 39:9-38. 